\title{
What constitutes a histological confirmation of cancer? A survey of terminology interpretation in two English regions
}

\author{
P Silcocks, M Page
}

\begin{abstract}
Aims-To compare interpretation by cancer registries and histopathologists of phrases that might confirm a diagnosis of cancer.

Methods-One hundred and thirty one consultant pathologists were sent a questionnaire containing 37 phrases used in pathology reports, including those indicating cancer and those not. Pathologists were asked to indicate whether each phrase confirmed the disease, ruled it out, or was uncertain, together with a subjective estimate of how frequently they used the phrase.

Results-There was a $58 \%$ response rate with similar interpretation between regions. There were some differences in frequency of use. At least $50 \%$ of respondents considered 12 terms as confirmatory (for nine the lower $95 \%$ confidence limit was greater than $66 \%$ ).

Conclusions-The registry should consider ignoring four of the 13 terms currently regarded as confirmatory. Terminology used in pathology reports should be standardised across registries. Registries and coding departments should use empirical evidence to assess which phrases confirm a diagnosis.

(F Clin Pathol 2001;54:246-248)
\end{abstract}

Keywords: communication; cancer registration; medical records; terminology; surgical pathology

Some cancer registries receive registrations passively from clinical coding departments, as in the Trent NHS Region, whereas others employ their own staff to seek out and abstract case notes, as in East Anglia. In either type of registry, it is necessary to decide whether a case has been histologically confirmed. Because pathologists do not use standard descriptions, sometimes it is not clear whether the pathology report has confirmed the presence of malignancy or merely indicates suspicion. If the latter, it is not histologically confirmed, although there may be additional clinical, radiological, or laboratory evidence to support a diagnosis of cancer. In Trent, clinical coders are encouraged to notify the registry of all potential cases, and it is part of the registry's task to decide which cases should be weeded out, by querying those cases where the histological evidence appears insufficient and requesting further clinical details.

Typically, cancer registries will have a list of qualifiers to help interpretation-for example, "diagnostic of . .." confirms cancer, whereas "reminiscent of . . ." does not. However, such lists seem to lack empirical evidence for their validity. On the other hand, such evidence can be obtained, as in a previous study ${ }^{1}$ on this topic, which examined the interpretation of 13 phrases by 20 pathologists in South Wales.

\section{Methods}

By pooling phrases used in Trent, East Anglia, and in the Irish Cancer Registry we produced a list of 37 qualifiers ranging from "rules out", through "apparently", to "diagnostic of". All consultant histopathologists in Trent and East Anglia were sent a questionnaire listing the phrases in random order. The pathologists were asked to indicate whether each phrase confirmed a diagnosis, ruled it out, or was uncertain by circling the appropriate response. At the same time, we similarly obtained a subjective estimate of how frequently (often/rarely/ never) the pathologists used each phrase.

If two adjacent terms were both indicated, the response was coded to the less certain one. For example, if "uncertain" and "yes" were both circled then the response was coded as "uncertain". Six pathologists gave some responses of this type, covering 28 items.

If two adjacent terms were marked, but with an arrow leading from one to the other, the coded term was that to which the arrow pointed. For example, if "uncertain" was circled but an arrow pointed to "yes" then it was coded as "yes". Three pathologists (including one of the above six) gave some responses of this type, covering 12 items.

The proportion of "confirm" responses was estimated for each phrase, and 95\% confidence limits (CL) obtained by logistic transformation (to avoid values outside the range $0-1$ ). For proportions of zero, an upper 95\% CL was found using the "rule of three"2.

Comparisons of the responses in each region were performed by trend $\chi^{2}$ tests on the two $2 \times 3$ tables corresponding to each phrase. Data manipulation and analysis were performed in Excel $^{3}$ and Systat. ${ }^{4}$ A second mailing was distributed to those who did not respond the first time.

\section{Results}

In Trent, 45 of 76 and in East Anglia 31 of 55 questionnaires were returned, giving an overall response rate of $58 \%$.

Concerning the interpretation of the phrases there was little difference in the pattern of responses between East Anglia and Trent, with 
Table 1 Phrase and percentage of pathologists stating it confirms a diagnosis

\begin{tabular}{|c|c|c|c|c|}
\hline Phrase & \% "Confirm" & $L C L$ & $U C L$ & $\begin{array}{l}\text { Number of } \\
\text { respondents }\end{array}$ \\
\hline Diagnostic of & $98.7 \%$ & $91 \%$ & $100 \%$ & 78 \\
\hline Characteristic of & $96.1 \%$ & $88 \%$ & $99 \%$ & 77 \\
\hline Represents & $95.9 \%$ & $88 \%$ & $99 \%$ & 74 \\
\hline Appearances of & $94.9 \%$ & $87 \%$ & $98 \%$ & 78 \\
\hline Typical of & $90.9 \%$ & $82 \%$ & $96 \%$ & 77 \\
\hline Indicates & $90.5 \%$ & $81 \%$ & $95 \%$ & 74 \\
\hline Indicative of & $89.6 \%$ & $80 \%$ & $95 \%$ & 77 \\
\hline That of & $89.2 \%$ & $80 \%$ & $95 \%$ & 74 \\
\hline Show & $85.1 \%$ & $75 \%$ & $92 \%$ & 74 \\
\hline Consistent with & $70.5 \%$ & $59 \%$ & $80 \%$ & 78 \\
\hline In keeping with & $65.8 \%$ & $54 \%$ & $76 \%$ & 76 \\
\hline Compatible with & $62.2 \%$ & $50 \%$ & $73 \%$ & 74 \\
\hline Most likely & $32.9 \%$ & $23 \%$ & $45 \%$ & 73 \\
\hline Rules out & $31.5 \%$ & $22 \%$ & $43 \%$ & 73 \\
\hline Appears to be & $25.0 \%$ & $16 \%$ & $36 \%$ & 72 \\
\hline Highly suspicious of & $23.4 \%$ & $15 \%$ & $34 \%$ & 77 \\
\hline Apparently & $22.2 \%$ & $14 \%$ & $33 \%$ & 72 \\
\hline Likely & $20.3 \%$ & $12 \%$ & $31 \%$ & 74 \\
\hline Suggestive of & $18.4 \%$ & $11 \%$ & $29 \%$ & 76 \\
\hline Favours & $18.4 \%$ & $11 \%$ & $29 \%$ & 76 \\
\hline Suggests & $14.5 \%$ & $8 \%$ & $25 \%$ & 76 \\
\hline Probable & $12.0 \%$ & $6 \%$ & $22 \%$ & 75 \\
\hline Seems to be & $10.8 \%$ & $5 \%$ & $20 \%$ & 74 \\
\hline Suspicious of & $10.5 \%$ & $5 \%$ & $20 \%$ & 76 \\
\hline Reminiscent of & $8.5 \%$ & $4 \%$ & $18 \%$ & 71 \\
\hline Presumed & $6.8 \%$ & $3 \%$ & $15 \%$ & 74 \\
\hline Appearances approaching & $5.5 \%$ & $2 \%$ & $14 \%$ & 73 \\
\hline Not ruled out & $5.3 \%$ & $2 \%$ & $14 \%$ & 75 \\
\hline Worrisome & $4.0 \%$ & $1 \%$ & $12 \%$ & 75 \\
\hline Questionable & $3.9 \%$ & $1 \%$ & $12 \%$ & 77 \\
\hline Suspects & $2.8 \%$ & $1 \%$ & $11 \%$ & 72 \\
\hline Risk of & $1.4 \%$ & $0 \%$ & $10 \%$ & 70 \\
\hline May be & $1.4 \%$ & $0 \%$ & $9 \%$ & 74 \\
\hline Possible & $1.3 \%$ & $0 \%$ & $9 \%$ & 75 \\
\hline Not excluded & $0.0 \%$ & - & $4 \%$ & 74 \\
\hline Equivocal & $0.0 \%$ & - & $4 \%$ & 76 \\
\hline Could be & $0.0 \%$ & - & $4 \%$ & 74 \\
\hline
\end{tabular}

Phrases in bold are regarded as definitive.

LCL, lower 95\% confidence limit; UCL, upper 95\% confidence limit.

Table 2 Frequency of use

\begin{tabular}{|c|c|c|c|c|}
\hline Phrase & $\%$ “Often” & $L C L$ & $U C L$ & $\begin{array}{l}\text { Number of } \\
\text { respondents }\end{array}$ \\
\hline Diagnostic of & $72.4 \%$ & $61 \%$ & $81 \%$ & 76 \\
\hline Characteristic of & $52.6 \%$ & $41 \%$ & $64 \%$ & 76 \\
\hline Represents & $48.6 \%$ & $38 \%$ & $60 \%$ & 74 \\
\hline Appearances of & $76.6 \%$ & $66 \%$ & $85 \%$ & 77 \\
\hline Typical of & $50.6 \%$ & $40 \%$ & $62 \%$ & 77 \\
\hline Indicates & $43.4 \%$ & $33 \%$ & $55 \%$ & 76 \\
\hline Indicative of & $30.3 \%$ & $21 \%$ & $41 \%$ & 76 \\
\hline That of & $66.2 \%$ & $55 \%$ & $76 \%$ & 74 \\
\hline Shows & $78.1 \%$ & $67 \%$ & $86 \%$ & 73 \\
\hline Consistent with & $84.4 \%$ & $75 \%$ & $91 \%$ & 77 \\
\hline In keeping with & $53.2 \%$ & $42 \%$ & $64 \%$ & 77 \\
\hline Compatible with & $45.3 \%$ & $34 \%$ & $57 \%$ & 75 \\
\hline Most likely & $22.4 \%$ & $14 \%$ & $33 \%$ & 76 \\
\hline Rules out & $7.9 \%$ & $4 \%$ & $16 \%$ & 76 \\
\hline Appears to be & $13.0 \%$ & $7 \%$ & $22 \%$ & 77 \\
\hline Highly suspicious of & $48.1 \%$ & $37 \%$ & $59 \%$ & 77 \\
\hline Apparently & $6.6 \%$ & $3 \%$ & $15 \%$ & 76 \\
\hline Likely & $9.2 \%$ & $4 \%$ & $18 \%$ & 76 \\
\hline Suggestive of & $42.1 \%$ & $32 \%$ & $53 \%$ & 76 \\
\hline Favours & $37.7 \%$ & $28 \%$ & $49 \%$ & 77 \\
\hline Suggests & $39.5 \%$ & $29 \%$ & $51 \%$ & 76 \\
\hline Probable & $24.0 \%$ & $16 \%$ & $35 \%$ & 75 \\
\hline Seems to be & $2.6 \%$ & $1 \%$ & $10 \%$ & 77 \\
\hline Suspicious of & $57.1 \%$ & $46 \%$ & $68 \%$ & 77 \\
\hline Reminiscent of & $5.3 \%$ & $2 \%$ & $13 \%$ & 76 \\
\hline Presumed & $3.9 \%$ & $1 \%$ & $12 \%$ & 76 \\
\hline Appearances approaching & $5.3 \%$ & $2 \%$ & $13 \%$ & 76 \\
\hline Not ruled out & $7.9 \%$ & $4 \%$ & $16 \%$ & 76 \\
\hline Worrisome & $9.1 \%$ & $4 \%$ & $18 \%$ & 77 \\
\hline Questionable & $4.0 \%$ & $1 \%$ & $12 \%$ & 75 \\
\hline Suspects & $9.7 \%$ & $5 \%$ & $19 \%$ & 72 \\
\hline Risk of & $5.4 \%$ & $2 \%$ & $14 \%$ & 74 \\
\hline May be & $6.5 \%$ & $3 \%$ & $15 \%$ & 77 \\
\hline Possible & $21.1 \%$ & $13 \%$ & $32 \%$ & 76 \\
\hline Not excluded & $20.3 \%$ & $13 \%$ & $31 \%$ & 74 \\
\hline Equivocal & $15.8 \%$ & $9 \%$ & $26 \%$ & 76 \\
\hline Could be & $9.2 \%$ & $4 \%$ & $18 \%$ & 76 \\
\hline
\end{tabular}

Phrases in bold are regarded as definitive.

LCL, lower 95\% confidence limit; UCL, upper 95\% confidence limit. $\mathrm{p}<0.05$ for only one of the 37 comparisons. For frequency of use, four of the 37 comparisons were significant (two with $0.04<\mathrm{p}<0.05$ and two with $\mathrm{p}<0.005$ ). All were no longer significant after allowing for multiple comparisons, so for the remaining analyses the results for each region were pooled.

Table 1 displays, for each phrase, the proportion of pathologists regarding it as "confirming" a diagnosis, together with 95\% $\mathrm{CL}$ and the denominator of the proportion. These vary slightly because some respondents omitted some items. For 12 phrases, at least $50 \%$ of pathologists regarded the expression as confirmatory, whereas for nine of these phrases the lower $95 \%$ CL was at least $66 \%$ (these are shown in bold), and they were therefore regarded as "definitive". Table 2 shows the reported frequency of use of each phrase.

\section{Discussion}

The aim of our study was not to provide a formal, comprehensive overview of this topic, but rather to draw attention to a real problem faced by cancer registries, and indicate possible solutions. Several papers have been published over the years dealing with issues such as the workload implied by an increasing overall information content of pathology reports ${ }^{5}$ and the value of checklists and standardised reports ${ }^{67}$ to achieve consistency in the content of clinically relevant information. Similar issues apply to radiological diagnosis. ${ }^{8} \mathrm{With}$ regard to phraseology, the most pertinent comment $^{9}$ described how ambiguous or misinterpreted terminology could have disastrous consequences, and yet be unappreciated by pathologists. However, the paper in question cited Attanoos and colleagues ${ }^{1}$ as its prime source, thus emphasising the lack of primary data in this area-which of course will always be specific to particular languages. Gall ${ }^{10}$ also described the uncertainty of pathological diagnosis: "I think it is cancer but don't hold me to it", but only briefly and in an anecdotal way.

In brief, the principal findings of our study were that only a limited number of terms in a pathology report are regarded by pathologists as confirming a diagnosis of cancer. Our study used a much larger number of phrases than that of Attanoos et al, ${ }^{1}$ and covered more than one health region. On the other hand, our response rate was only $58 \%$ compared with $100 \%$. Nevertheless, it was encouraging that the pathologists in two regions were consistent in their interpretation, and that our results were similar to those found in Wales by Attanoos et al: "diagnostic of", "characteristic of", "represents", "indicative of", "that of", and "shows" were definitive in both studies, although our definitive terms included two that were nondefinitive in the Welsh study, plus four that were not used at all.

We were puzzled by one apparent paradox: $11 \%$ regarded "highly suspicious of" as confirmatory compared with $23 \%$ who regarded "suspicious of" as confirmatory. In addition, at first we were slightly surprised that "rules out" was considered to exclude a 
diagnosis by only $59 \%$ of pathologists, but on reflection it is clear that the pathologist can only give an opinion on the specimen and not the patient.

In terms of frequency of use, our pathologists used "diagnostic of" more often, "that of" and "in keeping with" less often, and "consistent with" at about the same frequency as in the Welsh study. These are of course self reported figures. However, we reviewed 548 reports from East Anglia and 400 from Trent (restricted to the four laboratories that report to the Trent Cancer Registry) and found a rank correlation of 0.68 between the frequency with which terms appeared in the report and the proportion of pathologists who claimed they "frequently" used the terms. Although this is encouraging, it is not definitive because there is a large subjective element when analysing the text of reports, and our results are not entirely representative.

We were relieved to find that the changes we might want to make were relatively small. We need not change the terms that we currently regard as not being confirmatory, and of the 13 "confirm" terms currently used, we might drop four, namely:

- "Probable"

- "Likely"

- "Most likely"

- "Appears to be".

We now have an empirically justified list of phrases that, when used in pathology reports, can be taken to confirm the presence of cancer. Moreover, in Trent we can reduce our workload by only querying those notifications from coding departments that use nonconfirmatory terms.
In the future, pathologists and clinical coders in our regions need to be educated to describe what has been done. The advent of a standard format for pathology reports might help, but not all pathologists like ticking boxes, and not all anatomical sites will as yet have a standard format for reporting. Advocates of automated pathology coding will also need to incorporate the uncertainties of terminology in their algorithms. ${ }^{11}{ }^{12}$ Meanwhile, there should perhaps be moves at the national level (through the UK Association of Cancer Registries, The National Centre for Coding and Classification, and the Royal College of Pathologists) towards a standard terminology.

1 Attanoos RL, Bull AD, Douglas-Jones AG, et al. Phraseology in pathology reports. A comparative study of interpretation among pathologists and surgeons. $f$ Clin Pathol 1996;49:79-81

2 Eypasch E, Lefering R, Kum CK, et al. Probability of adverse events that have not yet occurred: a statistical reminder. BMF 1995;311:619-20.

3 Microsoft $^{\circledR}$ Excel 97 manual. Redmond WA: Microsoft Corporation 1985-1997.

4 Systat manual v 8. Chicago: SPSS Inc, 1998.

5 Cross SS, Bull AD. Is the informational content of histopathological reports increasing? F Clin Pathol 1992;45:
hes histopath $179-80$.

6 Kempson RL. The time is now. Checklists for surgical pathology reports [editorial]. Arch Pathol Lab Med 1992; 116:1113-19

7 Leslie KO, Rosai J. Standardization of the surgical pathology report: formats, templates, and synoptic reports. Semin Diagn Pathol 1994;11:253-7.

8 Lafortune M, Breton G, Baudouin JL. The radiological report: what is useful for the referring physician? Can Assoc Radiol f 1988;39:140-3.

9 Heffner DK, Adair CF. Clarity on the diagnosis line (the devil is in the details). Ann Diagn Pathol 1999;3:187-91.

10 Gall EA. Insight into the language of the tissue pathologist. Transactions of the Association of Life Insurance Medical Directors of America 1972;55:21-37.

11 Coles EC, Slavin G. An evaluation of automatic coding of surgical pathology reports. F Clin Pathol 1976;29:621-5.

12 Moore GW, Berman JJ. Automatic SNOMED coding. Proc Anпu Symp Comput Appl Med Care 1994:225-9.

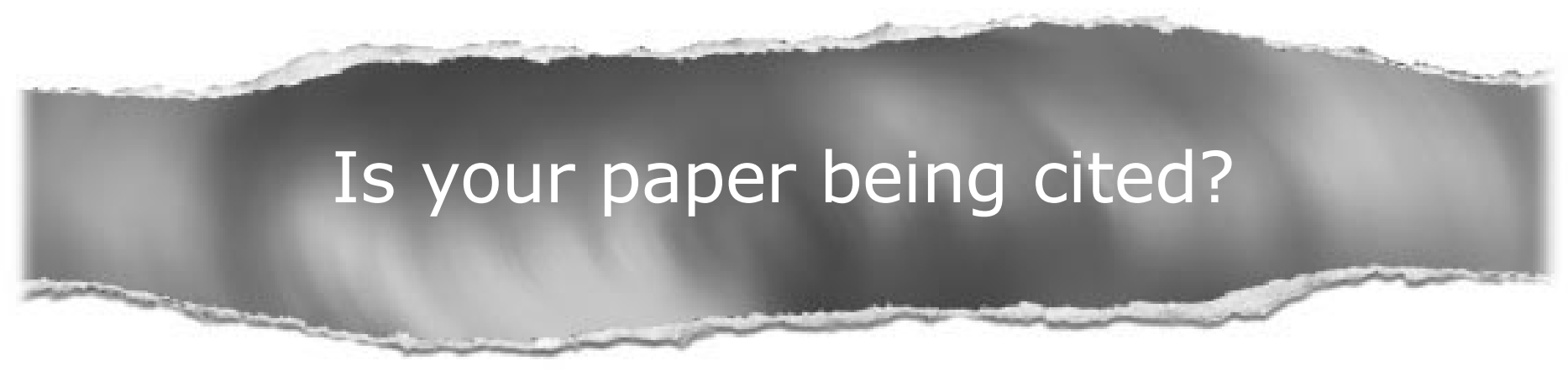

CiteTrack service

CiteTrack will alert you by email whenever new content in the Journal of Clinical Pathology or a participating journal is published that matches criteria you want to track

Topics: Tell CiteTrack which words or subjects to watch for in new content Authors: Be alerted whenever key authors you are following publish a new paper Articles: Know whenever a paper of interest to you is referenced by another paper

\section{www.jclinpath.com}

